$41(3) \mid 2012$

Recomposiciones territoriales de las periferias de las metrópolis andinas

\title{
Movilidad e inclusión social : la experiencia desde la periferia de Medellín y el primer Metrocable
}

Mobilité et inclusion sociale : l'expérience de la périphérie de Medellín et du premier Metrocable

Mobility and social inclusion: the experience of the Medellin periphery and the first metrocable

\section{Laure Leibler y Peter Brand}

\section{OpenEdition \\ Journals}

\section{Edición electrónica}

URL: http://journals.openedition.org/bifea/147

DOI: 10.4000/bifea.147

ISSN: 2076-5827

Editor

Institut Français d'Études Andines

Edición impresa

Fecha de publicación: 31 diciembre 2012

Paginación: 363-387

ISSN: 0303-7495

Referencia electrónica

Laure Leibler y Peter Brand, « Movilidad e inclusión social : la experiencia desde la periferia de Medellín y el primer Metrocable », Bulletin de I'Institut français d'études andines [En línea], 41 (3) | 2012, Publicado el 01 agosto 2013, consultado el 05 noviembre 2020. URL : http://journals.openedition.org/bifea/147 ; DOI : https://doi.org/10.4000/bifea.147

\section{c) $(7) \Theta$}

Les contenus du Bulletin de l'Institut français d'études andines sont mis à disposition selon les termes de la licence Creative Commons Attribution - Pas d'Utilisation Commerciale - Pas de Modification 4.0 International. 


\title{
Movilidad e inclusión social: la experiencia desde la periferia de Medellín y el primer Metrocable*
}

\author{
Laure Leibler** \\ Peter Brand ${ }^{* * *}$
}

\section{Resumen}

En 2004, en Medellín, se inauguró el primer cable aéreo urbano utilizado como transporte público semimasivo. No solo es un proyecto técnicamente novedoso, sino también socialmente inédito, ya que pretende conectar los barrios populares de la zona nororiental al resto de la ciudad. Este artículo propone ver en qué medida el proyecto de cable aéreo, llamado Metrocable, ha venido redefiniendo la noción de periferia, acercando los barrios marginados y haciendo más visible la presencia del Estado mediante proyectos urbanos. Se plantea la necesidad de considerar, más allá de los aspectos de movilidad, los impactos en el territorio y en su imagen, para entender hasta qué punto la implementación de una infraestructura como el Metrocable expresa y realiza la voluntad política de inclusión social y territorial, modificando la relación de la ciudad con su periferia.

Palabras clave: transporte urbano, movilidad, planeación urbana, inclusión social, Metrocable, Medellín

* Este artículo está basado en el proyecto de investigación Transport et justice spatiale, le cas du Metrocable de Medellín, Colombie realizado por Laure Leibler entre 2008-2010, en cumplimiento de su tesis de maestría en Ciencias Sociales en la École des Hautes Études en Sciences Sociales (EHESS), París, Francia. A su vez, cuenta con el respaldo de aportes provenientes del proyecto «Gobernanza local, movilidad urbana y reducción de la pobreza: lecciones de Medellín, Colombia», del Development Planning Unit - University College London, Universidad de los Andes, Universidad Nacional de Colombia; proyecto financiado por el ESRC y DfID del Reino Unido.

** École des Hautes Études en Sciences Sociales (EHESS), París, Francia. E-mail: laureleibler@gmail.com

*** Escuela de Planeación Urbano-Regional, Universidad Nacional de Colombia, sede Medellín. E-mail: pbrand@unal.edu.co 


\title{
Mobilité et inclusion sociale : l'expérience de la périphérie de Medellín et du premier Metrocable
}

\section{Résumé}

En 2004 est inauguré à Medellin le premier téléphérique de transport urbain. C'est un projet novateur techniquement et socialement puisqu'il permet de désenclaver les quartiers populaires de la zone Nord-Est de la ville. Cet article analyse dans quelle mesure ce projet de télécabine, appelé Metrocable, a permis de redéfinir la notion de périphérie en rapprochant des quartiers autrefois marginalisés et de rendre la présence de l'État plus visible à travers des projets urbains. Il invite a considérer au-delà des questions de mobilité, les impacts du Metrocable sur le territoire et les imaginaires pour comprendre dans quelle mesure celui-ci traduit une volonté politique d'inclusion sociale et territoriale et vient modifier la relation de la ville avec sa périphérie.

Mots clés : transport urbain, mobilité, planification urbaine, inclusion sociale, Metrocable, Medellín

\section{Mobility and social inclusion: the experience of the Medellin periphery and the first metrocable}

\begin{abstract}
In 2004, the first urban aerial cable-car public transport system was introduced in the city of Medellín, Colombia. It is both a technically and socially innovative response to urban transport problems since it uses an application of ski-slope technology to connect the Northeast low-income areas of Medellín to the city. The Metrocable gave more visibility to the state action through urban planning. This paper considers how this project has been redefining the notion of periphery by reducing the distance between once marginal neighborhoods and the heart of the city. It outlines the impacts both in terms of mobility and spatial transformation in order to understand how such an infrastructure can be the expression of the political will of social and territorial inclusion and change the relation between the city and its periphery.
\end{abstract}

Key words: urban transport, mobility, urban planning, social inclusion, Metrocable, Medellín

\section{INTRODUCCIÓN}

En 2004 se inauguró la primera línea de cable aéreo como sistema de transporte público semimasivo en la ciudad de Medellín, Colombia. La construcción de la Línea K del Metrocable fue una experiencia innovadora, ya que se aplicó a un sector de bajos ingresos de la ciudad una tecnología más asociada a la industria turística. Constituye una respuesta económica, rápida y visible a los problemas de transporte urbano y de movilidad en la ciudad. Ha contribuido a transformar la imagen de Medellín a nivel internacional, y ha suscitado el interés de numerosas ciudades de América Latina, Europa y Asia. Recientemente sistemas similares han sido implementados no solo en Colombia sino también en Caracas y en Río de Janeiro, y están proyectados en varias ciudades de otros países. 
En este trabajo se pretende explorar la relación entre un sistema de transporte y la periferia urbana y, más específicamente, la experiencia de la periferia desde el punto de vista de los habitantes a partir de una nueva opción de movilidad. En este sentido, podría argumentarse que el Metrocable transforma radicalmente la noción de periferia desde un ángulo técnico. Entre la estación terminal de la Línea A y el centro de la ciudad hay una distancia de $10 \mathrm{~km}$ y una diferencia de $350 \mathrm{~m}$ de altitud (fig. 1). La utilización del Metrocable-Metro permite hacer el viaje, una vez montado al sistema, en menos de 20 minutos. En otras palabras, el Metrocable reduce significativamente, hasta casi eliminar, la idea de la periferia entendida como condición geográfica, distanciamiento u obstáculo espacio-temporal.

De ahí surge una primera aproximación a la noción de inclusión. Barrios relativamente inaccesibles por las condiciones topográficas del sector y la pobre dotación de infraestructura vial, se volvieron de un día para otro, una parte sistémica de la ciudad mediante una articulación ágil al sistema de transporte masivo. Además, alrededor del Metrocable la ciudad realizó una serie de intervenciones urbanísticas para afianzar la integración a nivel local; proyectos arquitectónicos y urbanos que en cierta forma reproducen la ciudad formal y estructurada, en medio de las grandes expansiones homogéneas de vivienda que caracterizan a los sectores populares de la ciudad.

Dentro de esta misma lógica técnico-racional, se desprende una serie de expectativas en cuanto a la capacidad de una infraestructura de transporte de promover otras formas de integración económica y social. Mayor movilidad conlleva, desde este punto de vista, una mejor accesibilidad a oportunidades de trabajo, la posibilidad de mejores ingresos, más participación en la vida cultural y cívica de la ciudad. En principio, el Metrocable constituye un vehículo hacia el «derecho a la ciudad» y una mayor participación de los sectores marginados en la vida urbana plena. En este trabajo se indagan tales supuestos desde la experiencia de los usuarios del Metrocable y la experiencia de los pobladores1.

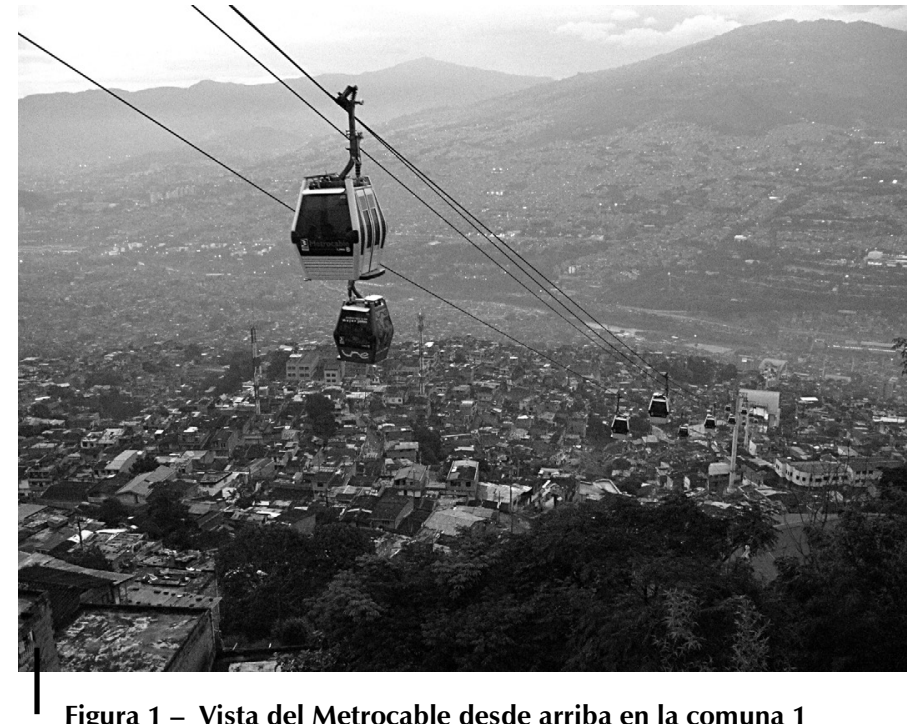

Figura 1 - Vista del Metrocable desde arriba en la comuna 1 Foto: Julio Dávila

1 Para ello, ese artículo se basa en particular en los resultados de una encuesta de percepción por cuestionario realizada en los barrios aledaños al Metrocable en el año 2009. 


\section{EL METROCABLE EN SU CONTEXTO}

La Línea K del Metrocable fue construida en la zona nororiental de la ciudad (fig. 2), atravesando la comuna 1 (Popular) y la comuna 2 (Santa Cruz), dos sectores construidos por medio de la invasión de terrenos y el loteo pirata a lo largo de los años 1950-1960. Su configuración espacial fue el resultado de la «ocupación ilegal de tierras con habitantes inmigrados del campo a la ciudad y sus procesos de legalización e inserción a la cuidad» (Zapata, 2009: 28). Al finalizar el siglo XX este fue uno de los sectores más densos de la ciudad, con un promedio que superó los 400 habitantes/ha. Su acceso era difícil como consecuencia del crecimiento urbano por autoconstrucción y procesos informales de urbanización, con poca presencia estatal en la organización del territorio más allá del suministro

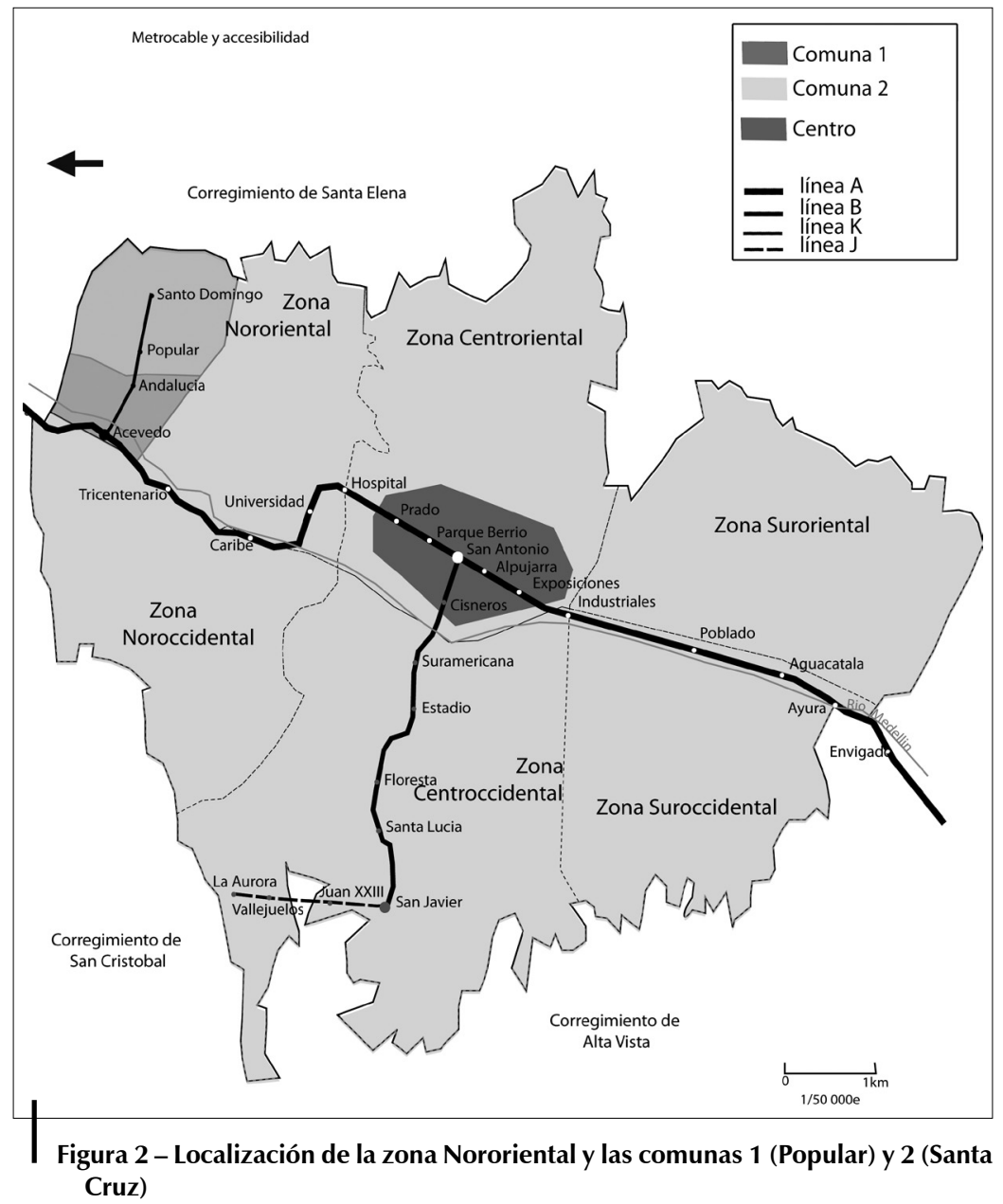

Elaborado por Laure Leibler, mayo de 2010

Fuente: Alcaldía de Medellín 
de servicios públicos. La topografía empinada hizo aún más difícil la adecuación de una infraestructura vial y el transporte público era brindado por empresas privadas a través de las limitadas vías de acceso, en su mayor parte negociando las tortuosas rutas hacia el centro de la ciudad.

La introducción de un sistema de Metro en 1995 hizo aún más evidente las limitaciones de accesibilidad del sector, pues la línea principal del Metro (que corre al lado del río que cruza longitudinalmente la ciudad) tenía pocas vías de acceso a las estaciones y no se logró dar acceso desde las partes altas de las laderas. La idea de un cable aéreo era atractiva en la medida que permitiría superar estos obstáculos y atraer a nuevos usuarios al sistema Metro, el cual en ese entonces funcionaba con un número de pasajeros/día muy por debajo de su capacidad. La misma empresa Metro de Medellín (propiedad del municipio de Medellín y del departamento de Antioquia) desarrollaba estudios técnicos a lo largo de los años 1990, sin que la idea figurara todavía en el debate sobre la ciudad y los planes de desarrollo urbano.

En 2001, el Metro de Medellín presentó la propuesta del Metrocable a los candidatos a la alcaldía, resaltando también sus beneficios en cuanto a la posibilidad de conectar los barrios populares y marginados con el resto de la ciudad. Sin embargo, la propuesta de un cable aéreo en un sector urbano como este no tenía antecedentes. Existían estudios que demostraban su factibilidad técnica y económica, pero la osadía de la idea provocó escepticismo y algo de burla en el mundo político, donde fue tildado de «juguete». El único candidato que se comprometió con el proyecto, Luis Pérez, resultó ganador de las elecciones.

El Metrocable se insertó en dos grandes líneas del plan de desarrollo de la ciudad para el periodo 2001-2003: la justicia social y el desarrollo de la competitividad (Alcaldía de Medellín, 2001). Las comunas 1 y 2 tenían graves problemas de desempleo (3 veces superior al promedio de la ciudad) y de pobreza, agudizados por una crisis económica y la necesidad de restructuración de la economía de la ciudad desde los años 1980 (Brand, 2005). Al mismo tiempo, el municipio sufría serias dificultades financieras producto de las deudas contratadas para la construcción del Metro de Medellín. Adicionalmente, este sector de la ciudad se encontró en el epicentro de la violencia asociada con el narcotráfico, cuando Medellín pasó a ser la ciudad más violenta del mundo con una tasa de 381 homicidios/100 000 habitantes en 1992. Este y otros sectores se volvieron casi ingobernables, con altos índices de sicariato y la presencia de bandas, milicias y otros actores armados.

Las comunas 1 y 2 resultaron altamente estigmatizadas y la imagen que se tenía de ellas antes de la llegada del Metrocable era la de un sector marginado, pobre, violento y fuera de control, tal como se evidencia en el siguiente artículo de la prensa local:

«¿Cuál es la gran obra de inversión en la comuna 2? A simple vista... ninguna, e indagando con quienes la conocen... tampoco. [...] $60 \%$ de la población está desocupada. De los afortunados, pocos trabajan en la industria, algunos en construcción y otros tantos en empleos domésticos. El resto, son independientes: venden confites en el centro o transforman 
la parte delantera de la casa en tienda. Como en las otras comunidades de estratos bajos, en la 2 la Iglesia sigue siendo la única que no da la espalda. $\mathrm{Ni}$ siquiera en los momentos en que la guerra arrecía entre callejones estrechos. La calma aparente de los últimos días puede continuar o alimentar el enfrentamiento que tiene en la escasez una causa y una excusa. Abandono, una excusa para la guerra. La presencia de jóvenes a toda hora del día en las esquinas no es más que el indicador de los niveles de desocupación y falta de oportunidades que tienen quienes habitan en la comuna 2, conformada por los barrios La Isla, El Playón de los Comuneros, Pablo VI, La Frontera, La Francia, Andalucía, Villa del Socorro, Villa Niza, Moscú 1, Santa Cruz y La Rosa. Para un líder del sector, no hay argumentos para criticar la actitud de estos muchachos cuando no se les ofrece nada. Ellos salen de la primaria, algunos hacen bachillerato y se acabó. Por eso, cualquier oferta que implique dinero la aceptan, no importa que sea ilícita. La fuente consultada asegura que en los últimos meses se ha visto mucho movimiento de dinero proveniente de grupos armados al margen de la ley, que ven en el abandono estatal y la falta de oportunidades el mejor argumento para conseguir colaboradores» (El Colombiano, 2002).

Dadas estas condiciones sociales, junto con la débil presencia de las instituciones legítimas del Estado, el sector cayó bajo el control de organizaciones de la mafia. Bajo su influencia, grupos juveniles luchaban por el control territorial para dominar el negocio del microtráfico de drogas y la extorsión de las rutas de buses y pequeños negociantes. Una de las consecuencias fue el recorte de la libre circulación de personas por las fronteras invisibles que se erigían entre los barrios y dentro de estos². La periodista Paula Cristina Pérez, en el artículo «Popular 1 y 2 reclaman el derecho a la vida» del periódico El Colombiano, del 28 de noviembre de 2001, escribe:

«Los habitantes de los barrios Popular 1 y 2 no aguantan más. La situación de violencia en el sector es insostenible y, sienten, se les salió de las manos. [...] Las fronteras imaginarias que trazan los más de diez combos que operan en el sector impiden el libre tránsito. Así, se impide el acceso a los servicios de salud, recreación y educación».

El Metrocable incursionó en un sector que presentaba serias deficiencias de accesibilidad, además de graves problemas de pobreza, desigualdad, criminalidad y falta de control del Estado. Alain Reynaud decía al principio de los años 1980 que:

«hablar de justicia socioespacial nos obliga a evocar la planeación del territorio, la intervención del Estado en la vida de una formación social para modificar más o menos de forma profunda la repartición de los equipamientos y actividades en el territorio» (Reynaud, 1981: 32).

2 Sobre ese tema, se puede consultar los resultados de la investigación «Archivo de lo(s) excluido(s). Memorias y construcción de futuro en el Barrio Popular n. ${ }^{\circ} 1$ de Medellín», realizada por el Instituto de Estudios Regionales (INER) de la Universidad de Antioquia, 2009.

3 Pequeños grupos delincuenciales, pandillas. 
Este tipo de intervención estatal en pro de la reducción de las desigualdades, implica voluntad política. Sin embargo, la situación era complicada en el caso de las periferias populares de Medellín, ya que restablecer la presencia, el control y la legitimidad del Estado requería enfrentar poderosas organizaciones ilegales y reprimir por lo menos parcialmente una extensa economía subterránea. El Metrocable ofreció una alternativa estable y segura de movilidad, no solo para los residentes del sector hacia el resto de la ciudad, sino también para facilitar el acceso al sector de las instituciones del Estado y la rama formal de la economía local (fig. 3).

Así, el Metrocable se convierte en un proyecto de afirmación territorial y de gobernanza, al igual que un proyecto de justicia social, con la idea de mejorar las condiciones de vida de los habitantes de uno de los sectores más desfavorecidos de Medellín. Esa voluntad de inclusión social y territorial se ve reforzada con la acción de la administración siguiente, que explota sistemáticamente el potencial

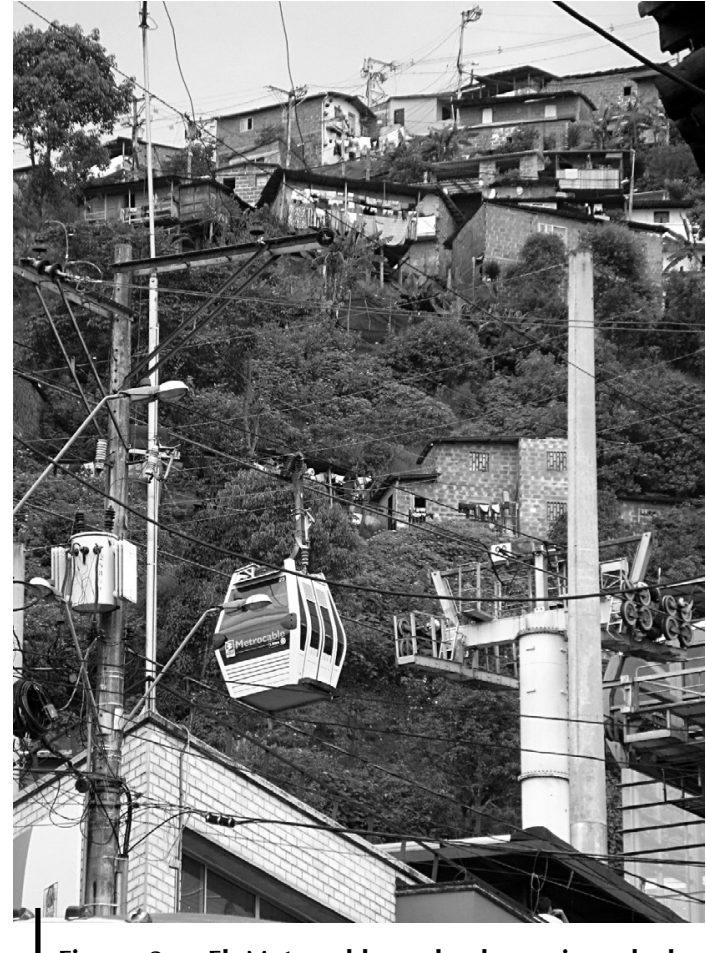

Figura 3 - El Metrocable, volando encima de los barrios de la Comuna 1

Foto: Julio Dávila transformador del Metrocable mediante un conjunto de obras urbanísticas complementarias. El alcalde independiente Sergio Fajardo (2004-2007) propuso como meta pagar la «deuda social y territorial» que la ciudad tenía frente a este y otros sectores pobres y abandonados de las periferias urbanas, empezando por la zona donde se construyó la primera línea del Metrocable (Dávila, 2009).

La Línea K se convirtió en el eje y prototipo para intervenciones posteriores, organizadas a partir de lo que se denominó Proyecto Urbano Integral (PUI). Los PUI propusieron integrar el cable aéreo al tejido urbano con el objetivo de impulsar nuevas dinámicas de desarrollo local, mediante un conjunto de intervenciones involucrando al transporte al igual que al medio ambiente, a la vivienda y al espacio público (Empresa de Desarrollo Urbano, 2010). A su vez, los PUI formaron parte de una política más amplia de mejoramiento urbano de los sectores pobres de la ciudad, con la construcción de parques-biblioteca, escuelas de alta calidad y una inversión constante y elevada en la educación y el acceso a las nuevas tecnologías. Esa política adquirió el nombre de «urbanismo social» (Echeverri \& Orsini, 2010), aunque el impacto social y la sostenibilidad de esos proyectos en el largo plazo son todavía inciertos (Brand, 2010).

Esta contextualización permite poner de relieve la importancia de la imaginación y voluntad políticas en el empeño de mejorar las condiciones de vida de los habitantes 
de los sectores populares. Se puede asimilar a un acto de justicia socioespacial (Musset, 2009), en la medida en que no solo representan la concretización de discursos en este sentido, sino también por la forma como se implementaron los principios de justicia al momento de construir el cable aéreo: valoración justa de los predios al momento de la compra, empleo de la mano de obra local para la construcción de la infraestructura, sistema extenso de consultación comunitaria, etc. Dicho esto, los discursos que han hecho de Medellín un modelo de ciudad tienden a desconocer o descuidar el análisis de los impactos sociales y territoriales reales de esta obra pública.

\section{METROCABLE, ACCESIBILIDAD Y JUSTICIA ESPACIAL}

\section{1. Accesibilidad, derecho a la ciudad y justicia espacial}

Si en una primera instancia la periferia se puede definir por su lejanía espacial respecto del centro, la cuestión de la movilidad desde y hacia ella se vuelve un elemento crucial para entender el grado de relaciones entre el centro y sus periferias, y entre las distintas periferias de la ciudad. La falta de movilidad puede convertir la marginalización geográfica en una fuerte exclusión social (Ureta, 2008). La movilidad no homogeneiza la sociedad, sino más bien la diferencia y polariza dando la libertad a algunos de actuar a distancia, en parte desconectados de algunos vínculos espaciales, mientras otros están encerrados en un lugar específico (Bauman, 2000).

En países en vía de desarrollo, los más pobres tienen limitaciones en cuanto al número de viajes que pueden realizar a diario debido a su bajo nivel de ingresos, lo que podría a su vez limitar sus posibilidades de mejorar. Ureta (2008) encuentra, en su estudio de las implicaciones de los costos de transporte para las personas que viven en las periferias de Santiago de Chile, que la ubicación impide la capacidad de caminar y que, a la vez, los altos costos del transporte público limitan la movilidad de las personas a lo estrictamente necesario (educación y empleo). Como consecuencia, esa movilidad restringe la participación de las personas en la vida urbana, las posibilidades de ampliar sus perspectivas laborales, diversificar sus actividades sociales y de recreo, y sobre todo de ejercer un compromiso político y cívico.

Así, más allá de la movilidad, lo que está en juego es la accesibilidad efectiva a los recursos de la ciudad. La estructura social y espacial de la ciudad genera desigualdades de acceso. Influyen tanto el nivel socioeconómico (los recursos disponibles para movilizarse) como otros criterios, tales como la edad, el género y la estructura familiar. Esas diferenciaciones se combinan con una diferenciación espacial, como observan Dureau \& Levy:

«El tamaño de la ciudad y la amplitud de las desigualdades que marcan el sistema de transporte condicionan la accesibilidad a los lugares de la ciudad para los distintos grupos sociales; ahí también los habitantes están 
en situaciones muy diferenciadas en cuanto a sus posibilidades de realizar sus desplazamientos cotidianos» (Levy \& Dureau, 2002: 401).

De esta manera, la movilidad transforma la noción misma de periferia. Al respecto comenta Allain:

«La movilidad contribuyó a relativizar la noción de proximidad. [...] La percepción de cercanía depende tanto de las capacidades financieras de los individuos como de sus representaciones» (Allain, 2005).

Hoy en día la noción de distancia se relaciona más con cuestiones de tiempo y costo, que con líneas métricas. La diferenciación espacial que opera en la ciudad, combinada con factores de discriminación social y segregación territorial, induce fuertes desigualdades en las posibilidades de acceder a los recursos urbanos.

En el caso de los países de América Latina:

«La escasez de los recursos públicos y la debilidad de los Estados, conjugadas con desigualdades sociales disparatadas y altos niveles de pobreza, no solo desencadenaron tratamientos diferenciados de los territorios, sino que aceleraron la concentración de los recursos públicos en algunos espaciosclave» (Musset, 2009: 62).

Algunos espacios se benefician de recursos públicos y por lo tanto atraen, mientras que otros espacios padecen de una falta de infraestructura. Este es el caso de la periferia, que tiende a caracterizarse por falencias en infraestructuras y servicios, a la vez que presenta dificultades para acceder a los «espacios clave». Reynaud (1981), al considerar los distintos grados de articulación de las periferias al centro, en una concepción crítica del modelo centro-periferia, nota que esta relación está sometida a grandes variaciones de acuerdo con el grado de intervención pública y las representaciones sociales.

Los centros se definen también en términos de accesibilidad, es decir en términos de la posibilidad de beneficiarse de los servicios e infraestructuras que ofrecen. En este sentido, son factores importantes la localización de infraestructuras y servicios, el conocimiento sobre la existencia de estos y el derecho de poder acceder a ellos. Aún si prevalece una política inclusiva, siempre existe un sentimiento de frustración para los habitantes que no pueden beneficiarse de los recursos que conocen pero que están fuera de su alcance. Sin la intervención del Estado, sea mediante inversión social o construcción de infraestructuras de servicios o de transportes, buena parte de la población de un territorio puede quedarse sin un verdadero acceso a la ciudad. Se puede considerar que tener acceso a los centros políticos, de representación, justicia, salud, empleo, educación, a los servicios públicos como el agua o la electricidad, es un derecho para el conjunto de los ciudadanos. Para Lefebvre, «[el derecho a la ciudad] se puede formular como un derecho a la vida urbana, transformada y renovada» (Lefebvre, 1968: 108). El Estado (en un Estado de Derecho) en la medida en que constituye la urbanidad en sí misma, es decir lo que hace la ciudad, debe garantizar la accesibilidad a esta. El Estado debe asegurar la virtualidad, potencialidad y perspectiva de poder beneficiar con recursos a las zonas periféricas si quiere mantener su presencia, el control territorial, el orden 
público y la gestión del territorio. Así, la acción del Estado en las periferias es clave para la efectividad de un derecho a la ciudad y para la disminución, o el incremento, de las disparidades espaciales en cuanto a la organización territorial en sí y en relación con la accesibilidad.

Sin embargo, en la negociación con el Estado para la obtención de recursos e infraestructuras, los grupos mejor organizados tienen ventaja (Harvey, 1973). Esto representa una desventaja para las periferias más marginadas y puede llevar a una acción estatal inequitativa. Así, para tener la cercanía a ciertos servicios, o al contrario la lejanía a ciertas externalidades negativas (como la contaminación, una planta de tratamiento de residuos sólidos o una zona de alto riesgo), los mejor dotados, los que pueden pagar el precio por una localización y que tienen las herramientas para negociar con el Estado, generalmente salen más beneficiados (Harvey, 1973).

El Estado, con sus intervenciones, puede transformar la desigualdad en injusticia si favorece a los territorios más dotados; o alternativamente puede transformar el espacio con el fin de reducir las disparidades, haciendo así un acto de justicia espacial. Si «hablar de justicia socioespacial obliga a evocar la planeación del territorio y la intervención del Estado en la vida de una formación social para modificar, más o menos profundamente, la repartición en el espacio de los equipamientos y las actividades» (Reynaud, 1981), es pertinente analizar el proyecto Metrocable desde la perspectiva de la justicia espacial.

Teniendo en cuenta lo anterior, la movilidad y la accesibilidad son factores fundamentales en la posibilidad de hacer realidad el derecho a la ciudad para los habitantes de los territorios marginados, y constituyen una dimensión clave en la permanencia, la disminución o el incremento de desigualdades sociales y espaciales. Una de las metas del proyecto Metrocable es la de acercar e incluir la zona nororiental al resto de la ciudad. No se trata solamente de acortar la distancia-tiempo entre este sector y el centro de Medellín, sino también de hacer llegar los servicios del Estado a estas comunas, utilizando el cable aéreo como puerta de entrada a la implementación de programas sociales y urbanísticos. El tema de la ciudad incluyente ha sido central en los planes de desarrollo local de las diferentes administraciones urbanas. Es necesario tener en cuenta el doble sentido de la accesibilidad: tanto para los habitantes del sector al resto de la ciudad como para los representantes del Estado a los sectores donde antes no podían acceder sin dificultades. Es decir, hay que diferenciar entre la racionalidad de la administración local y las lógicas de los habitantes en sus vidas cotidianas y entender el Metrocable también como una estrategia de normalización de las prácticas y una aspiración a una sociedad «formal» (Brand \& Dávila, 2011).

\section{2. Metrocable y movilidad: permanencia de las prácticas}

El reto de un proyecto de transporte reside en su efectivo impacto sobre la movilidad, en su capacidad de captar la demanda de transporte público (fig. 4). 


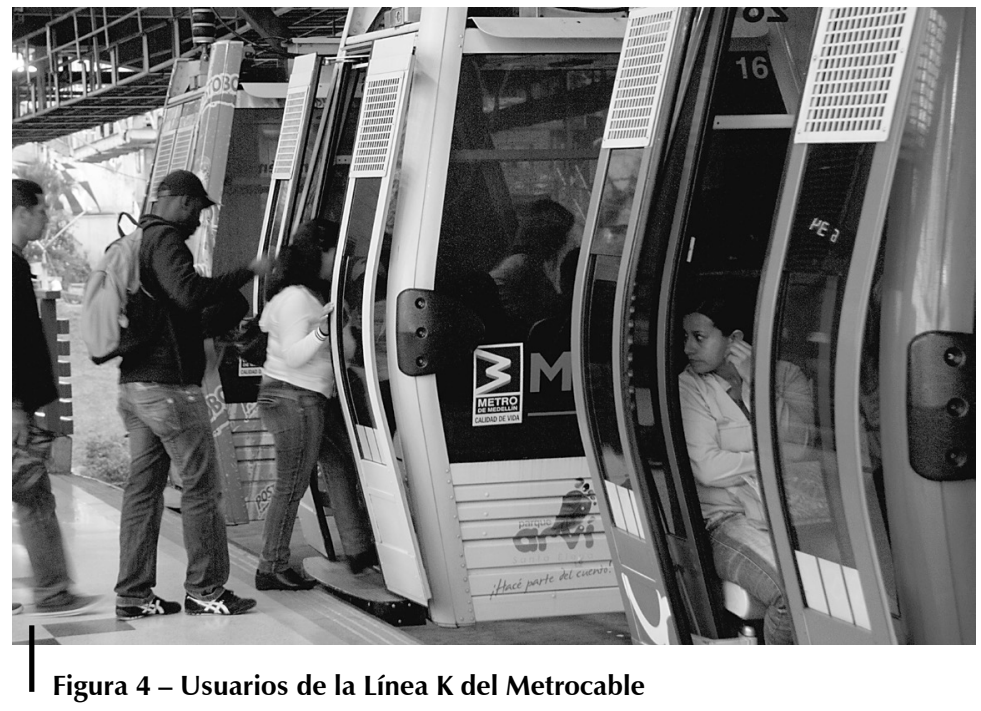

Foto: Natalia Pérez

En el caso de la Línea K del Metro de Medellín, la inversión de US\$ 23 millones buscaba mejorar la movilidad, reducir los tiempos de viaje, mejorar la calidad del transporte y su fiabilidad, y disminuir el costo de viaje para los usuarios, que anteriormente debían pagar dos viajes en bus (uno de la zona nororiental al centro y otro del centro a su lugar de destino). Antes de la inauguración del Metrocable, la oferta de transporte en las comunas 1 y 2 contaba con numerosas rutas de bus, principalmente hacia el centro de la ciudad.

Evaluar el impacto del teleférico urbano en Medellín es difícil por varias razones: en primer lugar porque esos impactos no son directos ni mecánicos, y en segundo lugar porque faltan datos estadísticos, especialmente en relación con los distintos aspectos de la vida «informal», lo que hace compleja la definición de grandes tendencias y relaciones de causalidad.

El cable aéreo tiene una capacidad máxima de 3000 pasajeros/hora y 30000 pasajeros/día, lo que equivale a un uso potencial para el 10 \% de la población de la zona de influencia directa del Metrocable, es decir de los barrios en los cuales hay una estación de Metrocable con acceso directo y fácil (alrededor de 150 ha y 150000 habitantes), y un $4 \%$ del total de los habitantes de las comunas 1 y 2. En horas pico, entre 5:00-8:00 am y 6:00-8:00 pm, el Metrocable es utilizado a su máxima potencialidad en un sentido, con largas filas de acceso y tiempos de espera. Ha logrado captar una parte importante de la demanda de transporte público, pero su alcance está limitado si consideramos el número de habitantes del sector, pese a que ellos constituyan potenciales usuarios. Tres factores pueden explicar esas cifras: la tarifa del Metro, la diferencia entre el perfil del usuario Metro y el del habitante de las comunas de la zona nororiental y las prácticas de movilidad. 
Los usuarios son principalmente trabajadores que tienen contrato en las industrias o que prestan servicios en otros barrios de la ciudad. Para ellos, el Metrocable representa un beneficio. Acceden al centro 20 minutos y pueden ir hasta las fábricas del sur de Medellín en aproximadamente 40 minutos, pagando un solo pasaje. Es el caso por ejemplo de Diana, habitante de 30 años del barrio Popular 2, que utiliza a diario el Metrocable para ir a trabajar a una fábrica de Itagüí. Ella se beneficia de la tarifa única cuando antes tenía que pagar dos pasajes en bus para ir a trabajar. Cuando hay una transferencia, el Metrocable permite ahorrar el $33 \%$ comparado con el costo de dos viajes en bus. Sin embargo, el acceso al cable puede involucrar largas caminatas, a veces en zonas empinadas y con un difícil acceso a las estaciones (numerosas escaleras, entre otros), y hacer cola en las horas pico puede durar hasta una hora. Así que el tiempo ahorrado con el Metrocable depende mucho de los trayectos realizados.

Por otra parte, para un recorrido directo, como por ejemplo hacia el centro de la ciudad, un bus convencional puede ser algo más barato y más rápido si se considera la caminata y la espera en los tiempos de viaje. En todo caso, el costo del transporte, en Metro/Metrocable o bus, es alto en relación con los ingresos de los habitantes del sector, la mayoría de los cuales no tiene un trabajo estable. Para los habitantes que ganan el salario mínimo, ir y volver de su lugar de trabajo le cuesta cerca de Col\$ 3 000/día o Col\$ 81 000/mes, lo que equivale a alrededor del $15 \%$ de sus ingresos, sin contar los gastos en transporte de los demás miembros de la familia.

Por lo tanto, las personas que tienen un trabajo informal o no tienen ingresos fijos, están obligadas a limitar sus desplazamientos a lo estrictamente necesario. Las subvenciones para los estudiantes universitarios benefician a pocos, ya que no son muchos los que acceden a la educación superior en el sector. En consecuencia, el costo del Metro/Metrocable hace que los jóvenes, los pensionados y las amas de casa lo utilicen apenas ocasionalmente. En el estudio exploratorio realizado a los habitantes del sector en 2009, la mitad de las personas entrevistadas afirmaron haber viajado solamente un par de veces en el Metrocable y solo dos mencionaron que nunca habían utilizado el sistema ${ }^{4}$. Así, la tarifa, que beneficia a las personas que pueden ahorrar dinero en largos trayectos para ir a trabajar en el sector formal se vuelve un limitante para el uso más generalizado del Metrocable.

Efectivamente, si bien la Empresa Metro afirma que el $88 \%$ de sus usuarios pertenecen a los estratos 1, 2 y 3, solamente el $8 \%$ viven en sectores socioeconómicos del estrato 1 (Metro de Medellín, 2009), y los estratos 2 y 3 son predominantes en la ciudad. El perfil típico del usuario del Metro, de acuerdo con las cifras del Metro de Medellín, es de un trabajador del sector formal (70 \%) y únicamente el $13 \%$ de los usuarios son del sector informal (Metro de Medellín, 2009). Esto contrasta fuertemente con el perfil del habitante de las comunas 1 y 2, donde la gran mayoría de los trabajadores se desempaña en el sector informal. Las normas de uso del Metro/Metrocable erigen otras barreras

4 Encuesta realizada en forma de cuestionario a 100 habitantes entre julio y noviembre de 2009. 
para el trabajador informal. Pedro, vendedor ambulante, habitante del barrio Popular 1, explica que no puede utilizar el Metrocable porque no le dejan subir con cargas pesadas y que de todas formas prefiere caminar hasta el centro para ahorrarse los costos de transporte.

Es importante aclarar que el Metrocable no ha transformado radicalmente las prácticas de movilidad de los habitantes del sector. Dinámicas anteriores al cable aéreo, como las costumbres en la vida cotidiana, el arraigo barrial y el control territorial (Echevarría Ramírez \& Rincón Patiño, 2000), influyen en los impactos a corto plazo de ese nuevo modo de transporte. El proyecto de cable aéreo no acaba de un día para otro con las lógicas implementadas desde hace medio siglo. El estudio exploratorio muestra que el $30 \%$ de los entrevistados no salen del barrio. Los jubilados salen del barrio principalmente para ir al médico o visitar a familiares, mientras los jóvenes se desplazan a pie hacia los barrios cercanos en sus actividades sociales y de diversión. Muchos entrevistados salen del sector, especialmente hacia el centro, «cuando les toca» y «para hacer vueltas», es decir, una vez al mes para cumplir con obligaciones administrativas. Es el caso de Diana, ama de casa del barrio Popular, quien hace sus desplazamientos cotidianos a pie en el barrio, y va una vez al mes a pagar los servicios públicos en el centro.

Caminar sigue siendo el medio de transporte más utilizado, ya que el $70 \%$ de los entrevistados realizan su movilidad diaria a pie, recorriendo distancias a veces largas. Se encuentra ahí una práctica de movilidad centrada en el barrio, en la línea de los estudios de movilidad realizados por Levy \& Dureau en Bogotá (Levy \& Dureau, 2002). Con excepción de trabajadores y jóvenes, muchos habitantes no sienten la necesidad de salir del barrio; como lo expresa una mujer adulta del barrio Popular, «para qué vamos a salir si tenemos todo aquí». El sustento económico y el tejido social se construyen principalmente en el barrio.

Al igual que en los barrios populares de otras ciudades colombianas, la mayoría de los habitantes de la zona nororiental realizan su vida económica y social dentro del sector, y su modo de transporte principal es caminar. En particular las mujeres, los jóvenes y los jubilados no sienten la necesidad ni tienen interés en gastar dinero en el transporte público si todo está en el barrio: la familia, las opciones de trabajo, los lugares de sociabilidad, etc. (resultados de las entrevistas, 2009). De esta manera, hay poca evidencia para sugerir que el Metrocable haya permitido el incremento en el número de viajes no esenciales y una mejor participación en la vida de la ciudad. Eso nos invita a repensar la relación entre movilidad, accesibilidad y derecho a la ciudad. Más allá del acceso a las centralidades, el derecho a la ciudad es un derecho a una vida urbana renovada (Lefebvre, 1968).

\section{3. Metrocable e inclusión social y espacial de la periferia}

El proyecto Metrocable, seguido por el PUI, tenía como objetivo promover la inclusión de las comunas de la zona nororiental a la ciudad, dotándola de infraestructuras de calidad como un teleférico urbano, una biblioteca, nuevos 
colegios, calles renovadas y proyectos locales de vivienda de interés social. El mejoramiento urbano de las periferias se planteó como una manera de reducir la exclusión y la estigmatización de esos barrios, asociados en el imaginario colectivo a la violencia urbana y a los problemas de pobreza. Esa apuesta evidencia la voluntad, por parte del gobierno local, de reducir desigualdades espaciales y de integrar esos barrios a las lógicas formales de la ciudad. Por eso es pertinente evocar las transformaciones notables en el territorio, pero también, después de ocho años de implementación, las permanencias.

Si bien el impacto sobre la movilidad es difícil de medir, las consecuencias de la inscripción del Metrocable en las comunas Popular y Santa Cruz también son complicadas de evaluar. La estimación, por ejemplo, del impacto del teleférico urbano en la economía local, los ingresos de las familias o los precios de las viviendas es problemático, en la medida en que hacen falta datos estadísticos oficiales. Pero también por la influencia de otras variables coyunturales como los ciclos económicos de corto plazo, los niveles de violencia y de conflicto en el sector, la persistencia de una migración bajo presión en la ciudad (desplazamiento, deslizamiento, desalojo) y de la implementación de otros programas complementarios en el mismo territorio. En particular, la implementación del PUI, tan estrechamente vinculado al proyecto Metrocable, hace difícil diferenciar los logros de cada uno de los proyectos tomado individualmente. Pero la observación de campo ha permitido destacar dos tendencias a nivel espacial.

En primer lugar, uno de los grandes logros del proyecto Metrocable ha sido integrar los barrios de las comunas Popular y Santa Cruz al territorio vivido de la ciudad. Lejos de ser una periferia incomunicada, los barrios del sector se han convertido en un lugar atractivo para el recreo de los habitantes de otros barrios de la ciudad, que van a conocer el Metrocable y el sector de Santo Domingo. El Metrocable posibilitó que los ciudadanos conozcan barrios donde no iban antes. Según la Empresa Metro, en su balance del año de la inauguración:

«La puesta en servicio del Metrocable despertó entre toda la comunidad de Medellín una actitud integradora haciendo que miles de personas Ilegaran hasta la zona nororiental para reconocer a sus conciudadanos, compartir su entorno y mirar la ciudad completa desde otra óptica» (Metro de Medellín, 2005: 36).

Efectivamente, en particular los fines de semana, turistas locales, nacionales y extranjeros van a conocer y disfrutar de los miradores, de la biblioteca de España y del Metrocable. El paisaje desde lo alto de la zona nororiental adquirió un valor de patrimonio paisajístico y se convirtió en una referencia en la ciudad. El Metrocable ha logrado no solo desarrollar una movilidad desde los barrios hacia la ciudad, sino también desde la ciudad hacia esos barrios con una accesibilidad mejorada. El carácter novedoso y la amplia publicidad alrededor de la obra, contribuyeron a ese flujo en ambos sentidos. Se podría decir que el Metrocable ha buscado desarrollar un derecho a la ciudad en beneficio de ambos, para que también los ciudadanos tengan acceso a la periferia y al ocio. La dimensión recreativa del Metrocable se ve reforzada hoy en día con la apertura de una línea hacia el parque 
natural Arví, en el corregimiento de Santa Elena, cable con fines recreativos que sale de la última estación de la Línea $\mathrm{K}$.

En segundo lugar, el Metrocable ha venido transformando el territorio, redefiniendo a escala comunal y barrial las relaciones de centralidades y de periferia. El Metrocable se ha pensado como eje integrador de los barrios dentro de las comunas de la zona nororiental. La ubicación de la infraestructura al límite de distintos barrios, en el lugar que durante mucho tiempo constituyó una frontera entre barrios y combos, no es una casualidad. El Metrocable, por su ubicación, tenía la potencialidad de beneficiar a nueve barrios. Pero su localización al margen del centro de los barrios, excepto en el caso del barrio Andalucía, se convierte en un reto para convertir las estaciones del Metrocable en centralidades.

Las estaciones y el eje del Metrocable (calle 107), se convirtieron en puntos de referencia para los habitantes del sector de influencia directa. Para los jóvenes, las estaciones se convirtieron en un punto de encuentro. Además, el Metrocable fue la puerta de entrada de servicios que no estaban presentes anteriormente como un banco o una oficina de la empresa de servicios públicos EPM. Todos los barrios no se han visto beneficiados de la misma manera por el Metrocable. Se puede observar en la figura 5 una especialización territorial vertical con un sector residencial y comercial renovado (Andalucía, Villa del Socorro), un sector residencial poco beneficiado por el mejoramiento urbano en particular de los espacios públicos (Granizal y Popular) y un sector residencial y una vocación turística (Santo Domingo Savio, La Esperanza) por los equipamientos construidos (parque biblioteca, plazoletas, etc.).

A escala de las comunas, el Metrocable ha venido redefiniendo las relaciones de centro y de periferia. Si bien, en la figura 2, parece estar en el corazón de las comunas 1 y 2, el Metrocable no es accesible para los habitantes de barrios que se encuentran en el otro vertiente de la ladera (Santo Domingo 2, Santo Domingo 1, sector de la Torre) por razones de topografía, ni para los que viven en el extremo sur de las comunas, muy lejos de las estaciones. Por otra parte, se ha favorecido la expansión urbana arriba de la estación de Santo Domingo, en zonas de alto riesgo no recuperable, creando nuevos barrios informales y autoconstruidos, como el barrio del Pinal.

De hecho, al mirar a escala comunal, los barrios de las comunas Popular y Santa Cruz conocieron un desarrollo muy heterogéneo. Los flancos de la ladera, del otro lado de la vertiente, lógicamente no se han beneficiado tanto de la obra. Esa falta de integración horizontal, incluso en algunas ocasiones dentro de los mismos barrios, se debe en parte a la difícil accesibilidad por causa de la topografía empinada. Hay una diferencia entre los sectores con influencia directa del Metrocable y los sectores de barrios (o barrios completos) de las mismas comunas que se encuentran fuera del alcance de la obra, sin haberse visto beneficiados por las políticas de renovación urbana. Así, no se puede generalizar el impacto del Metrocable en las comunas 1 (Popular) y 2 (Santa Cruz), sino ver las disparidades territoriales notorias entre diversos sectores (figs. 6, 7 y 8 ). Si bien es normal que el impacto de una infraestructura disminuya a medida que uno se aleja de ella, en la 
Laure Leibler, Peter Brand

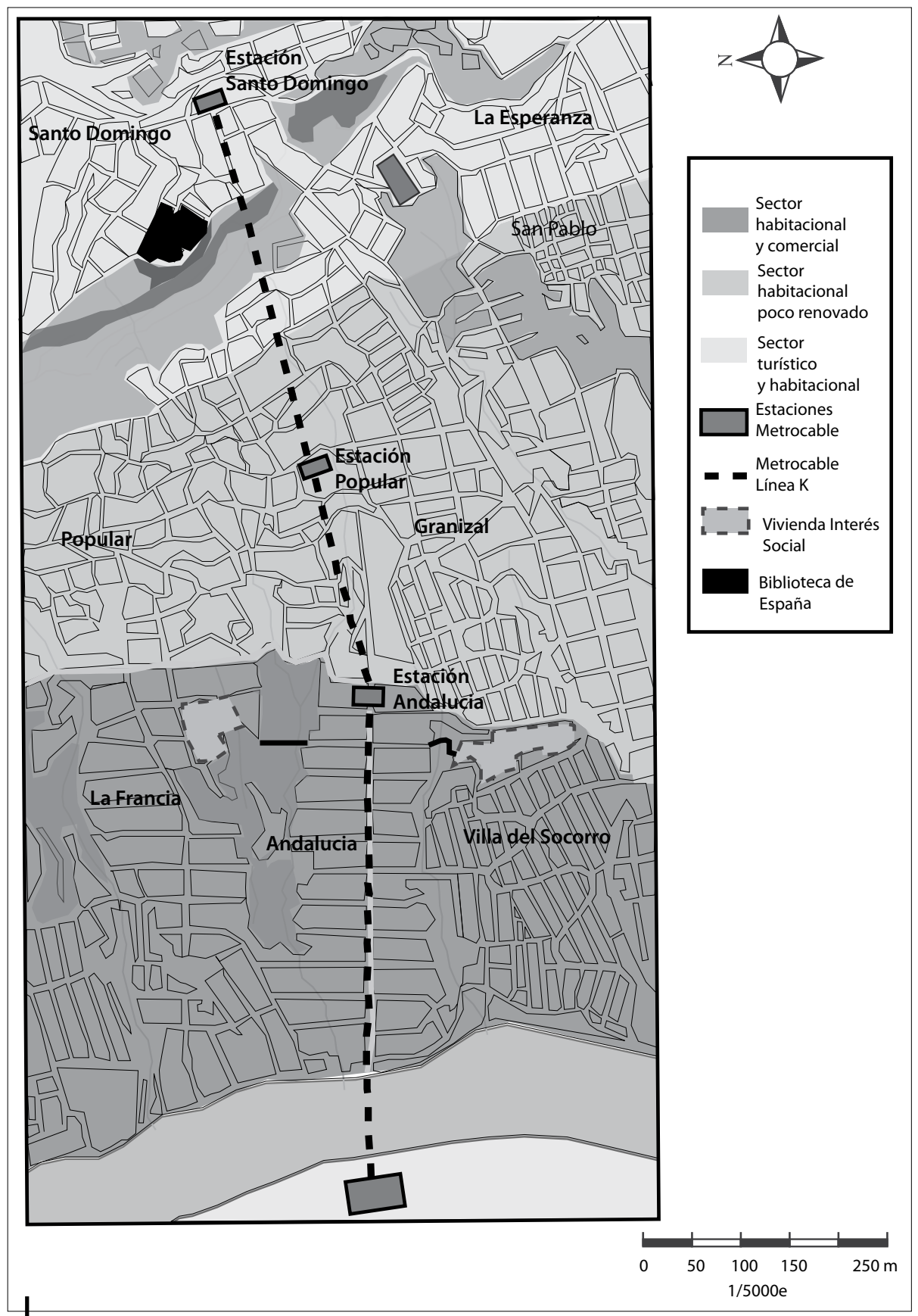

Figura 5 - Impacto diferenciado del Metrocable 
Movilidad e inclusión social: la experiencia desde la periferia de Medellín y el primer Metrocable

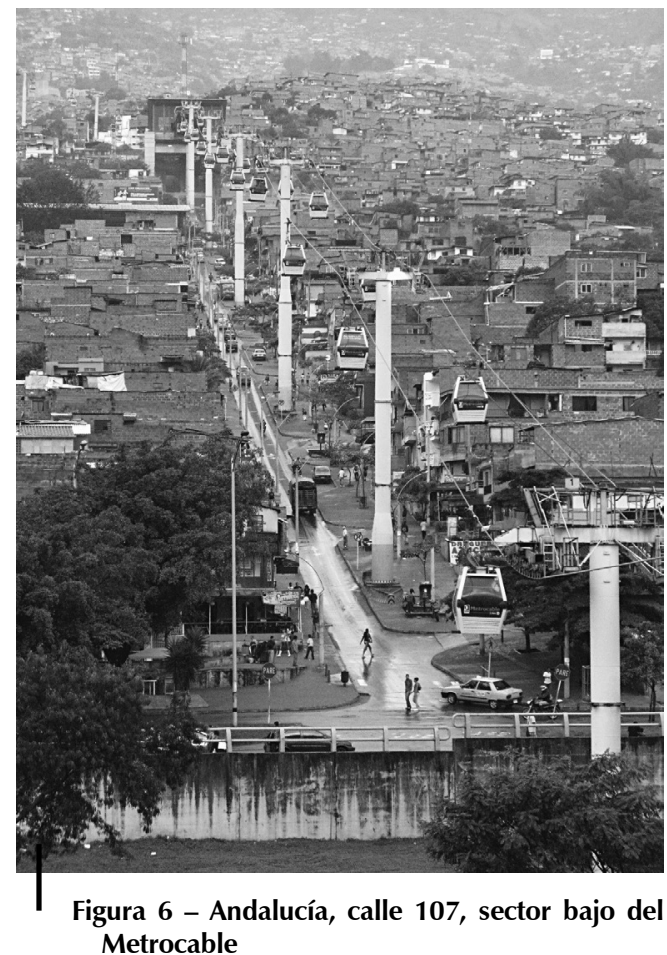

Foto: Julio Dávila

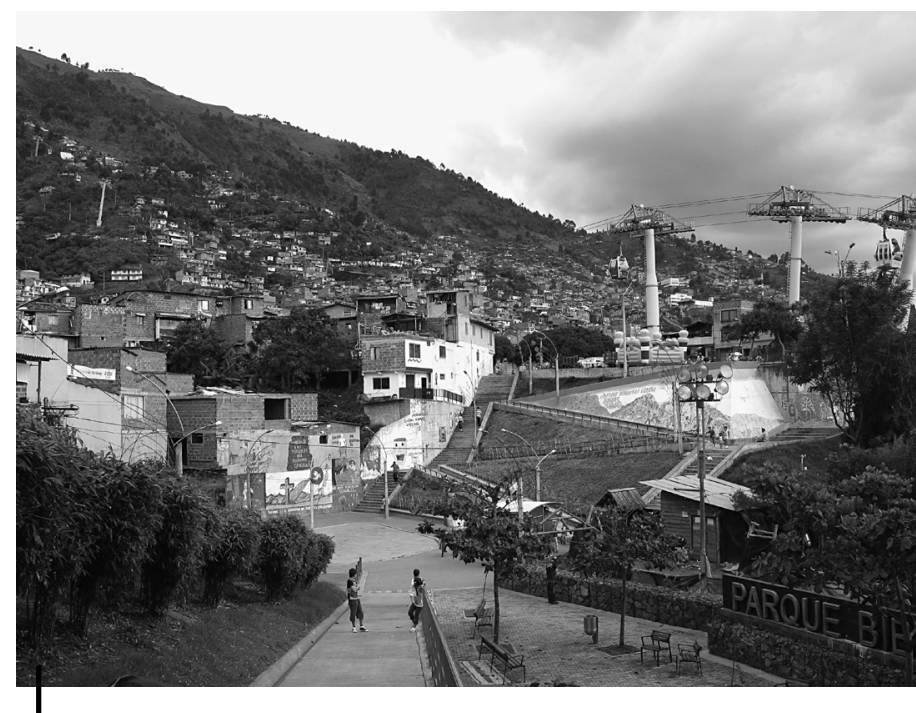

Figura 7 - Nuevos espacios públicos alrededor de la estación Santo Domingo Savio

Foto: Julio Dávila 


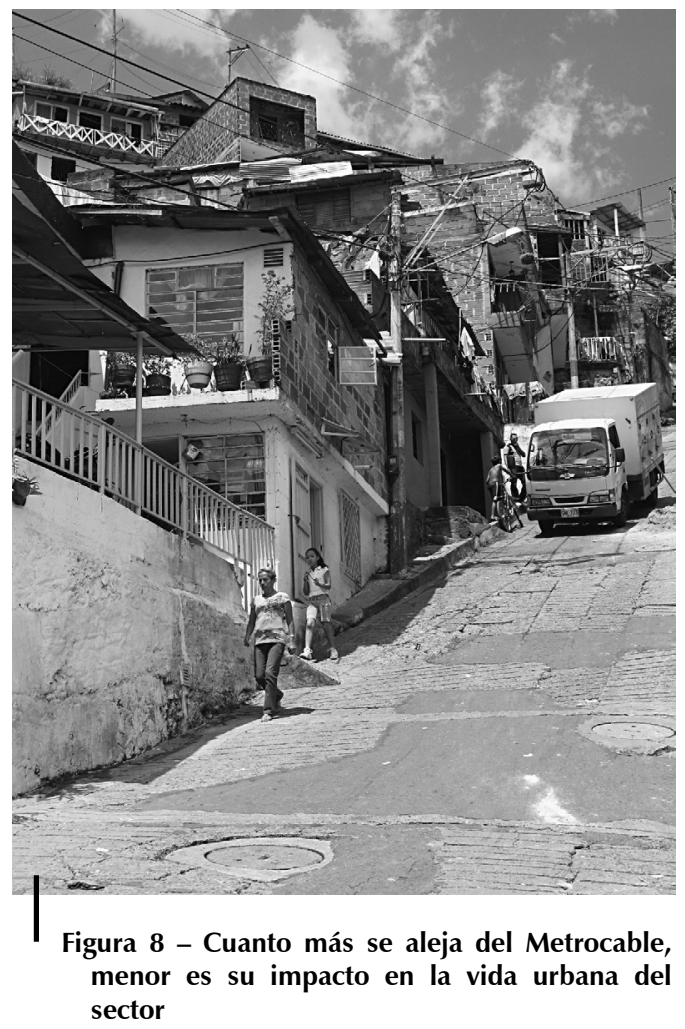

Foto: Julio Dávila

práctica no hay evidencia que las estaciones se hayan convertido en centralidades a escala comunal.

En tercer lugar, si bien el proyecto Metrocable ha sido presentado como un modelo de intervención, promovido como parte inicial y clave de una intervención integral, obviamente no ha permitido acabar con todas las problemáticas del sector. El Metrocable ha impulsado ese desarrollo económico porque atrae a personas al sector, pero es difícil medir el impacto sobre la economía de los hogares. Así, en la proximidad de las estaciones, se multiplicó la actividad comerciante, en particular en el sector bajo de la zona de influencia, en Andalucía, y en la parte alta, en Santo Domingo (específicamente en el sector de la calle Puerto Rico, en los alrededores de la estación). Muchos negocios se abrieron en los primeros pisos de las casas, pero a veces son personas externas al barrio las que invierten en un negocio.

Aunque la llegada de nuevos negocios dinamiza al barrio y es visto por el $70 \%$ de los entrevistados como una consecuencia positiva de la llegada del Metrocable, algunas personas evocan como contraparte un aumento de los costos de vida. Una adulta mayor viviendo en Andalucía dijo: 
«A mí, ¿a qué me sirve esos nuevos negocios bonitos si no tengo con qué comprar?».

Ningún estudio o cifra oficial permite respaldar que el Metrocable haya permitido reducir sensiblemente el desempleo o mejorar el acceso al empleo. La coyuntura económica de Medellín y su reconversión a una economía de servicios, ayuda a explicar la dificultad de conseguir empleo poco calificado o no calificado en la ciudad. El problema del desempleo va más allá del problema de acceder físicamente a los lugares que necesitan la mano de obra.

Así, los que están en la franja inmediata del Metrocable han podido resultar beneficiados por su ubicación, ya que tienen la posibilidad de desarrollar un comercio o de rentabilizar su bien inmobiliario, arrendando o vendiendo pisos o cuartos dentro de las casas. Sin embargo, no existe información que demuestra una mejora sensible del nivel socioeconómico general del sector. Por otra parte, aunque han bajado las tasas de homicidio en los últimos años, se reconoce la permanencia de grupos armados ilegales en el sector (Personería de Medellín, 2011). Y como último dato indicativo, según los líderes de la comuna 1, la comuna Popular es la que tiene mayor número de desconectados al servicio de electricidad (alrededor de 3000 hogares).

Lo anterior es sintomático de las dificultades económicas que permanecen en el sector y es un problema que se podría agravar si la Alcaldía sube la estratificación socioeconómica del sector. La estratificación social se evalúa de acuerdo con las características externas de la vivienda y al entorno urbanístico, para determinar a partir de allí el nivel de subvención de los servicios públicos. Lógicamente, la implementación de programas de renovación urbana y de infraestructuras debería, a mediano plazo, implicar una subida parcial de la estratificación, pese a que por voluntad política, hasta el momento, no se haya dado. La cuestión de la subida de la estratificación es una cuestión delicada. Si bien se valorizaron los bienes inmobiliarios, no hay cifras oficiales que permitan evaluar si se incrementaron los ingresos de las familias. Según un líder del barrio Popular, director de una asociación que promueve el desarrollo de la empresa local, «el efecto Metrocable para a la puerta de las casas». Aunque se requeriría un estudio integral de la situación económica de las comunas 1 y 2, un estudio sobre la construcción social del hábitat en la comuna 1 realizada en 2011 por la Escuela del Hábitat de la Universidad Nacional, mostró la permanencia de una heterogeneidad en las condiciones de vida, vivienda y hábitat en ese sector de la ciudad.

En conclusión, el Metrocable ha reconfigurado parcialmente los barrios de su zona de influencia directa pero no se puede decir que las comunas 1 y 2 no siguen siendo periferias de la ciudad. Si bien algunos sectores y barrios están ahora más integrados a las dinámicas de la ciudad, buena parte de las comunas está al margen de esa obra de infraestructura. El Metrocable ha venido reforzando el desarrollo heterogéneo de ese territorio. 


\section{3. «YA NO NOS VEN TAN POPULAREÑOS»: EL METROCABLE, REPRESENTACIONES Y GOBERNABILIDAD}

Un gran logro del proyecto Metrocable ha sido el de direccionar positivamente la mirada hacia los barrios periféricos de la zona nororiental de la ciudad. Ahora un sentimiento de orgullo y dignidad sobresale en el discurso de los habitantes de la zona a partir de esta nueva infraestructura. El Metrocable resignificó este sector urbano marcado por el narcotráfico y la violencia. El éxito del Metrocable, reforzado por las obras urbanísticas complementarias, tuvo amplias consecuencias sociales directas e indirectas, pues mejoró la imagen de este sector (desde afuera y desde adentro), y también impulsó una nueva presentación de Medellín al nivel nacional e internacional.

Nuestras investigaciones confirman el incremento de la autoestima de la comunidad y el sentido de inclusión que el cable aéreo y el proyecto urbano integral fomentaron. Cinco años después de su puesta en marcha, el discurso de los habitantes entrevistados no deja dudas al respecto. El Metrocable es una obra apreciada y la gente que vive en los barrios aledaños tiene la impresión que su bienestar fue tomado en cuenta y que sus condiciones de vida mejoraron considerablemente. «Antes, Medellín era lo mejor, pero solo de aquí pa' abajo», dijo un joven retomando a su manera el famoso lema de los paisas. Casi la totalidad de las personas entrevistadas durante el trabajo de campo (de junio a noviembre de 2009) consideró que el Metrocable ha sido una infraestructura beneficiosa y que indujo cambios positivos en el territorio. Más del 75 \% de los entrevistados opinó que el Metrocable no tuvo impactos negativos, el resto menciona principalmente la pérdida de ingresos por parte de los transportadores tradicionales. Además, la mayoría cree que el Metrocable permitió mejorar la movilidad, la seguridad, la calidad de vida y la valorización del barrio.

Según los habitantes, la seguridad fue reforzada, especialmente en las inmediaciones de las estaciones. La reducción en la tasa de homicidios suele ser asociada con la llegada del Metrocable, ya que este hecho coincidió con la inauguración del sistema de cable aéreo, aunque no existe una clara relación causal y evidentemente incidieron otros factores importantes. La sensación de mayor seguridad es, sin embargo, muy significativa. De acuerdo con los entrevistados, el Metrocable propició una mejoría en la oferta comercial, cultural y educativa, así como el comienzo del turismo hacia el sector. Aunque utilizan poco el Metrocable, los habitantes de las comunas Popular y Santa Cruz aprecian la posibilidad de desplazarse a todas partes de la ciudad con cierta facilidad y economía. El Metrocable permite que la ciudad se abra para los habitantes del sector, rompiendo el encerramiento que antes caracterizaba la vida barrial. También promueve nuevos deseos y abre nuevos horizontes para los jóvenes, por ejemplo en el campo de la educación tecnológica y universitaria.

El Metrocable viabiliza y materializa el orgullo de pertenecer a los barrios del sector nororiental de la ciudad. El cable aéreo y el parque-biblioteca España se convirtieron en referentes territoriales para los habitantes del sector. En el discurso 
de los habitantes, esto se refleja en la sensación de hacer parte del porvenir de la ciudad. Por cierto, la retórica de una transformación suele expresarse retomando palabras del discurso oficial. Aún así, puede entenderse como el principio de un cambio importante en las mentalidades de los residentes de estos sectores; habrá que estar atento a su devenir en los próximos años.

Los habitantes del sector están de acuerdo con la administración local, en el sentido que el Metrocable ha permitido reducir la estigmatización de los barrios de la zona nororiental. Al respecto, hay que notar que las representaciones de dichos barrios alimentan la historia urbana de la violencia, con sus ingredientes legendarios alrededor de la figura de los capos del narcotráfico, los sicarios, las pandillas y las prostitutas. Esta imagen fue popularizada y difundida por la literatura (novelas como La Virgen de los Sicarios de Fernando Vallejo y Rosario Tijeras de Jorge Franco, y sus respectivas adaptaciones cinematográficas) y telenovelas. Si bien tales representaciones se basan en una realidad de violencias plurales, polimorfas y dramáticas sufridas por estos barrios por lo menos desde los años 1980, se convirtieron en un cliché que fácilmente deslizaba hacia nociones segregacionistas y clasistas. En las representaciones amplias de la ciudad, la zona nororiental apareció como un alma condenada, acusada de contener o causar todos los problemas que padecía Medellín en tiempos de múltiples crisis.

Cinco años después de la llegada del Metrocable, tanto los habitantes como las instituciones están convencidos de que esas imágenes de violencia y miseria, que perjudicaban tanto a los habitantes de la zona como a la ciudad entera, ya pertenecen al pasado. Una señora, habitante del barrio Popular, al preguntarle por los cambios propiciados por el Metrocable exclama:

«iEs que usted no se da cuenta! iTodo ha cambiado! iYa no nos ven tan Populareños!».

Al usar la figura «Populareños», hace referencia simultánea al nombre del barrio/ comuna y las connotaciones negativas que el lugar había adquirido. De esa manera, la señora reclama una identidad barrial valorizada. Es interesante notar que el espacio nombrado, la toponimia, está en el centro de la afirmación del cambio; el imaginario así territorializado se expresa en el discurso.

No se puede confirmar si efectivamente la imagen de estos barrios y sus habitantes ya no padece de la mala fama de antes. Sin embargo, se puede aseverar que la mera presencia de estos discursos positivos en los barrios aledaños al Metrocable es un cambio significativo en sí. La integración que se planteó como un elemento importante del Metrocable, pasa por el reconocimiento en el imaginario colectivo de la pertenencia de estos barrios a la ciudad, en vez de ser el chivo expiatorio del temor y resentimiento ciudadano.

Sin lugar a dudas, la amplia e intensa estrategia de comunicación institucional también participa de manera determinante en la formación y transformación del lugar de las comunas en el imaginario colectivo de la ciudad. Sin embargo, frente a las nuevas representaciones oficiales promovidas por la administración municipal, las imágenes urbanas y los imaginarios ciudadanos están más apegados al pasado y resistentes a intentos de cambio amañado. Aún así, el hecho de 
la articulación fácil y acceso seguro a través del Metrocable, implica un paso importante en la recomposición de la imagen del sector y la reconfiguración de su participación en la ciudad.

La inauguración del Metrocable despertó una enorme curiosidad entre la ciudadanía en general. La posibilidad inédita de conocer directamente estos barrios de mitos y miedos produjo un flujo turístico sorprendente. Personas comunes y corrientes de Medellín y el departamento de Antioquia, y luego del resto del país e incluso extranjeros, se montaron en el Metrocable, a veces bajando en la estación terminal de Santo Domingo Savio, para disfrutar la vista desde el mirador adyacente o visitar el parque-biblioteca España. Tanto el desplazamiento en las cabinas como las estaciones mismas del Metrocable ofrecen la posibilidad de «mirar la ciudad completa desde otra óptica» (Metro de Medellín, 2005), desde arriba hacia abajo. Paisajes urbanos, vistas de la ciudad poco valoradas anteriormente, se convirtieron en un patrimonio paisajístico; lo que antes solo disfrutaban los habitantes del sector, ahora se volvió accesible a todos.

De esta manera, el «derecho a la ciudad» adquiere un doble sentido. Las clases media y alta pudieron disfrutar una oferta recreacional únicamente ofrecida por los barrios más marginales. Este fenómeno no es típico y seguramente tiene mucho que ver con la tecnología del sistema Metrocable y la experiencia kinestética que ofrece. También influye la fuerte identidad regional y la cultura local, que hace que los residentes del sector reciban a los visitantes con complacencia y agrado. El turismo se incrementó a partir de 2010 cuando se puso en operación otra línea del Metrocable que conecta la estación terminal de la Línea A con otra que conduce al parque Arví, una amplia zona verde de recreación ecológica.

Sin embargo, por muy original que sea este turismo interno, de fin de semana, no necesariamente rompe los prejuicios frente al sector. Contrario a lo que afirma la Empresa Metro, subir en el Metrocable, parar en la plaza rehabilitada del barrio Santo Domingo, no permite «compartir el entorno», por lo menos no más allá de compartir una vista desde unos pocos lugares adecuados especialmente para tal propósito. La contemplación turística es una forma de consumo que no implica compromiso alguno con el lugar (Urry, 1990). Además, la participación visual con el entorno revela, más allá de las intervenciones puntuales, un panorama urbano igual en apariencia que antes, y el turista percibe e intuye los estrictos límites de su presencia aceptable, límites tanto espaciales como temporales.

El Metrocable puede entenderse también como un dispositivo de normalización y regulación de los barrios informales de la ciudad. El cable aéreo lleva consigo normas sociales, reglas de comportamiento estrictas, una vigilancia cotidiana, un incremento de las informaciones registradas, etc. La mayoría de los habitantes acepta eso como algo necesario e incluso positivo, pese a que pueda provocar un grado de incomodidad, inconformidad o hasta resistencia. Sin embargo, esa forma de control social no alcanza los grupos y organizaciones ilegales que operan por fuera tanto de las normas culturales como de la ley misma.

No obstante, la creación de un sentido de inclusión a través del Metrocable y el mejoramiento urbano complementario, constituye un beneficio político 
interno y externo. La administración local ganó en legitimidad y gobernabilidad, mientras el impacto estético del cable aéreo y de una arquitectura de «calidad» en áreas urbanas pobres, fascina a los arquitectos y urbanistas del mundo entero. El Metrocable sirve de bandera a la promoción de una imagen de ciudad económicamente competitiva y socialmente incluyente, y la experiencia pionera de Medellín despertó un amplio interés entre numerosas ciudades y entre las agencias multilaterales de desarrollo. En contraste con los impactos modestos en términos de movilidad y de bienestar, el sistema Metrocable ha tenido un gran significado simbólico. Esa manipulación del mundo de los símbolos, en el contexto de un urbanismo contemporáneo del espectáculo, es sin duda un elemento importante y efectivo.

\section{CONCLUSIONES}

El proyecto Metrocable ha permitido redefinir la relación complicada de la ciudad con su periferia, facilitando el acceso desde y hacia los barrios beneficiarios. Fue la puerta de entrada para una mayor presencia del Estado que llegó con un enfoque territorial e integral clave. El teleférico urbano en Medellín ha sido un éxito (en términos de transporte, ciudad y sociedad), en la medida que forma parte de una política concertada de mejoramiento integral de áreas de bajos recursos. En ese sentido, cabe recordar que la inversión complementaria de los proyectos urbanos integrales fue siete veces superior al costo del cable aéreo, sin contar los costos de los programas sociales implementados en el área de influencia directa. De hecho, la segunda línea del Metrocable demostró que ese tipo de infraestructura requiere una cuidadosa integración al tejido social y a las redes espaciales, para que un incremento de la movilidad resulte en un mejoramiento urbano generalizado.

Quedan dudas sobre los efectos de los cables aéreos en la movilidad. Son utilizados por una minoría de habitantes del sector (menos del $10 \%$ ). Los beneficios para la economía local han sido pocos, y la valorización positiva del suelo y de las casas se ha limitado a los entornos directos del Metrocable. Si bien esos beneficios no deben ser subvalorados, considerando los relativamente bajos costos de implementación del cable aéreo, es importante subrayar la diferenciación espacial de los impactos entre y dentro de los barrios de la comuna Nororiental.

Así, los grandes beneficios giran alrededor del valor simbólico de los teleféricos. Esas infraestructuras de gran impacto visual tanto para los residentes como para los visitantes, crean una sensación de inclusión social y de integración en la ciudad moderna, fomentan el orgullo local y promueven la autoestima personal y barrial. Parte del éxito del proyecto Metrocable ha sido poner en el centro del debate la inclusión de las periferias y lograr que barrios antes marginados se convirtieran en el orgullo de la ciudad. Indiscutiblemente tuvo una buena acogida entre los habitantes, quienes consideran que ha cambiado todo. Desde los más altos mandos de la ciudad hasta los habitantes de la zona, es claro el cambio drástico dado a los discursos sobre esos barrios periféricos, antes estigmatizados y asociados a los problemas de violencia. Quizás el pulso 
político dado contra la exclusión territorial permita a largo plazo transformar las representaciones, pese a que mantenga a esos barrios en una posición pasiva de receptores de la infraestructura.

Sin embargo, el cable aéreo provoca interrogantes sobre la sustentabilidad del conjunto de proyectos de mejoramiento urbano, sin el soporte de un crecimiento económico que reduzca la pobreza, sin programas que incorporen a los ciudadanos en una vida urbana democrática de forma sistemática, sin una voluntad continua de reducir las desigualdades sociales y espaciales, en fin de brindar un derecho a la ciudad real y efectivo. La espectacular experiencia del Metrocable pierde su encanto al considerar como tela de fondo una pobreza casi intocada.

\section{Referencias citadas}

ALCALDÍA DE MEDELLíN, 2001 - Plan de desarrollo 2001-2004, Medellín competitiva; Medellín: Alcaldía de Medellín.

BAUMAN, Z., 2000 - Modernidad Líquida, 226 pp.; México: Fondo de Cultura Económica.

BRAND, P., 2005 - Urban Environmentalism: Global Change and the Mediation of Local Conflict, 256 pp.; Londres: Routledge.

BRAND, P., 2010 - El urbanismo social de Medellín, Colombia. Revista de Arquitectura, n. ${ }^{\circ}$ 359: 99-103; Madrid: Colegio Oficial de Arquitectos de Madrid.

BRAND, P. \& DÁVILA, J., 2011 - Mobility innovation at the urban margins. City, Vol. 15, n. ${ }^{\circ}$ : $647-661$.

DÁVILA, J., 2009 - Being a mayor: The view from four Colombian cities. Environment and Urbanization, Vol. 21, n. ${ }^{\circ}$ 1: 37-57.

ECHEVERRI, A. \& ORSINI, F., 2010 - Informalidad y urbanismo social en Medellín (Informality and social urbanism in Medellín). In: Medellín: Medio Ambiente, Urbanismo y Sociedad (M. Hermelin, A. Echeverri \& J. Giraldo, J., eds.): 130-152; Medellín: Universidad EAFIT.

ECHEVERRÍA RAMÍREZ, M.-C. \& RINCÓN PATIÑO, A., 2000 - Ciudad de territorialidades, polémicas de Medellín, 207 pp.; Medellín: CEHAP, Universidad Nacional de Colombia.

EMPRESA DE DESARROLLO URBANO, 2010 - ¿Qué es un PUI? Disponible en: http:// proyectosurbanosintegrales.blogspot.com/p/que-es-el-pui.html (consulta realizada en mayo de 2012).

HARVEY, D., 1973 - Social Justice and the City, 354 pp.; Londres: The University of Georgia Press.

LEFEBVRE, H., 1968 - Le droit à la ville, 166 pp.; París: Anthropos.

LEVY, J.-P. \& DUREAU, F. (eds.), 2002 - L'accès à la ville. Les mobilités spatiales en questions, 411 pp.; París: L'Harmattan.

METRO DE MEDELLíN, 2005 - Responsabilidad social, nuestra razón de ser, 177 pp.; Medellín: Metro de Medellín.

METRO DE MEDELLÍN, 2009 - Balance social 2008; Medellín: Metro de Medellín. 
Movilidad e inclusión social: la experiencia desde la periferia de Medellín y el primer Metrocable

MUSSET, A., 2009 - ¿Ceohistoria o geoficción? Ciudades vulnerables y justicia espacial, 266 pp.; Medellín: Editorial Universidad de Antioquia.

PÉREZ, P. C., 2001 - Popular 1 y 2 reclaman el derecho a la vida. El Colombiano (28 de noviembre); Medellín.

PÉREZ, P. C., 2002 - La Comuna 2, un desafío constante. El Colombiano (4 de noviembre); Medellín.

PERSONERÍA DE MEDELLÍN, 2011 - Informe sobre la situación de los derechos humanos en Medellín; Medellín: Personería de Medellín. Disponible en: http://www. personeriamedellin.gov.co/index.php/finish/62-informes/3823-informe-sobre-lasituacion-de-derechos-humanos-en-medellin-primer-semestre-2011.html

REYNAUD, A., 1981 - Société, Espace et Justice, inégalités régionales et justice sociospatiale, 263 pp.; París: PUF.

URETA, S., 2008 - To move or not to move? Social exclusion, accessibility and daily mobility among the low-income population in Santiago, Chile. Mobilities, Vol. 3, n. ${ }^{\circ}$ 2: 269-289.

URRY, J., 1990 - The Tourist Gaze, 176 pp.; Londres: Sage Publications.

ZAPATA HOYOS, I., 2009 - Plan de desarrollo y reconstrucción de la memoria cultural de la Comuna 1; Medellín: Alcaldía de Medellín. 